\title{
Assessment of the performance of the Chilbolton 3-GHz Advanced Meteorological radar for cloud-top height retrieval
}

\author{
C. M. Naud and J.-P. Muller \\ University College London \\ London, UK \\ E. C. Slack and C. L. Wrench \\ CCLRC-Rutherford Appleton Laboratory \\ Didcot, UK \\ E. E. Clothiaux \\ The Pennsylvania State University \\ University Park, PA, USA \\ Submitted to Journal of Applied Meteorology \\ February 4, 2004
}

Corresponding author address: Catherine Naud, now at NASA-GISS, Room 678, 2880

Broadway, New York, NY 10025, USA

cnaud@giss.nasa.gov

Tel: +1 21267855 72, fax: +1 2126785552 


\section{Abstract.}

The Chilbolton 3-GHz Advanced Meteorological Radar (CAMRa), which is mounted on a fully steerable 25 metre dish, can provide three-dimensional information on the presence of hydrometeors. We investigate the potential for this radar to make useful measurements of low-altitude liquid water cloud structure. In order to assess the cloud-height assignment capabilities of the 3-GHz radar, low-level cloud-top heights were retrieved from CAMRa measurements made between May and July 2003 and compared with cloud-top heights retrieved from a vertically pointing $94-\mathrm{GHz}$ radar that operates alongside CAMRa. The average difference between $94-\mathrm{GHz}$ and 3-GHz radar derived cloud-top heights is shown to be $-0.1 \pm 0.4 \mathrm{~km}$. In order to assess the capability of $3-\mathrm{GHz}$ radar scans to be used for satellite-derived cloud-top height validation, Multi-angle Imaging SpectroRadiometer (MISR) cloud-top heights were compared with both 94-GHz and 3-GHz radar retrievals. The average difference between $94-\mathrm{GHz}$ radar and MISR cloud-top heights is shown to be $0.1 \pm 0.3 \mathrm{~km}$ while the $3-\mathrm{GHz}$ radar and MISR average cloud-top height difference is shown to be $-0.2 \pm 0.6 \mathrm{~km}$. In assessing the value of the CAMRa measurements, the problems associated with low reflectivity values from stratiform liquid water clouds, ground clutter, and Bragg scattering resulting from turbulent mixing are all addressed. We show that in spite of the difficulties, the potential exists for CAMRa measurements to contribute significantly to liquid water cloud-top height retrievals leading to the production of twodimensional transects (i.e. maps) of cloud-top height.

\section{Introduction}

Realistic representations of clouds in climate models are important and currently a number of uncertainties pertaining to the representations of clouds in these models remain (IPCC, 2001). Accurate cloud observations are essential for improving model cloud parameterizations and in recent years several new ground- and satellite-based instruments have been designed and installed for accurately retrieving cloud properties. Ground-based measurement stations are of great importance for cloud monitoring and providing validation data for both satellite cloud property retrievals and model cloud outputs. Accurate measurements of cloud properties were an important goal of the Atmospheric Radiation Measurement (ARM) program when it established its Cloud And Radiation Testbed (CART) sites at locations in the United States and the tropical western Pacific (Ackerman and Stokes, 2003). Similar ground-based measurement capabilities also exist in Europe at Cabauw (The Netherlands), SIRTA (France) and the Chilbolton Facility for Atmospheric and Radio Research (CFARR, United Kingdom).

Using data from these sites, routine monitoring of clouds in an automated and continuous fashion is now possible. Some of the instruments hosted by these sites are passive (e.g. flux and radiance measurements, infrared and microwave radiometers, whole sky thermal infrared or visible cameras) and others are active (e.g. millimeter-wavelength cloud radars and lidars). Millimeter-wavelength cloud radars (MMCRs) have been shown to be suitable for the retrieval of cloud boundaries (Clothiaux et al., 2000) and have also been shown to be useful for validating satellite retrievals and model outputs (Hogan et al., 2000). However, these radars are usually operated in fixed vertically pointing mode, providing information on clouds in a narrow column $(\sim 50-150 \mathrm{~m})$ directly above the site. To produce 
two-dimensional observations of cloud-top fields, it would be necessary to scan the MMCRs in azimuth and elevation. At present none of the ground-based cloud remote sensing sites mentioned above possess scanning MMCRs.

The CFARR, which is situated in Hampshire (UK, $\left.51.15^{\circ} \mathrm{N}-1.43^{\circ} \mathrm{W}\right)$, hosts a wide range of instruments for cloud and atmospheric observations, most of them being automatically operated (see http://www.chilbolton.rl.ac.uk/). CFARR instruments include a 94-GHz vertically pointing radar, a $35-\mathrm{GHz}$ vertically pointing radar, a vertically pointing lidar-ceilometer, a zenith pointing visible camera with partial sky view, a multi-frequency micro-wave radiometer and an infrared whole sky camera. Also located at the site is the Chilbolton 3-GHz Advanced Meteorological Radar (CAMRa) that is mounted on a fully steerable dish of 25-m diameter (Goddard et al., 1994).

The CAMRa system consists of a large antenna providing high gain and a narrow beam, and a dual polarization capability that enables it to distinguish cloud and precipitation particle shapes and sizes. It has full Doppler capability for mapping winds in the line of sight direction. Radars such as CAMRa, which have a long wavelength compared to MMCRs, are less sensitive to small particles (e.g. Battan, 1973). A 3-GHz (i.e. 10-cm wavelength) radar is, therefore, not optimal for liquid water cloud detection, as liquid water cloud droplets are small compared to the wavelength and liquid water contents are generally low. Liquid water clouds are better detected with smaller wavelength radars, such as MMCRs with frequencies of $35-\mathrm{GHz}$ and $94-\mathrm{GHz}(8.5-\mathrm{mm}$ and $3.2-\mathrm{mm}$ wavelengths, respectively). However, because of the large antenna, the CAMRa system has a narrow beam and greater sensitivity than most other 3-GHz radars. As such, in areas where precipitation is not occurring, information on liquid water clouds can be obtained using CAMRa.

CAMRa has the ability to perform two-dimensional vertical slice measurements of reflectivity that can be combined to produce a three-dimensional representation of radar reflectivity from cloud. Possible applications of these multidimensional datasets include validation of satellite retrievals and contributions to the three-dimensional reconstruction of cloud fields for radiative transfer simulation studies. For example, the I3RC consortium (Intercomparison of 3D Radiation Codes, http://i3rc.gsfc.nasa.gov/) is currently focused on liquid water clouds because their microphysical and radiative properties are easier to simulate in the short-wave than for ice clouds. The present study was limited to the retrieval of cloud-top heights of only liquid water clouds. CAMRa is sensitive to ice particles and ice particle clouds generally return much stronger CAMRa signals than liquid water clouds. Because the approach that we envision for retrieving cloud boundaries for ice clouds using a 3-GHz radar is different from our current approach, observations of ice clouds with CAMRa will be the subject of a separate investigation.

This study investigated the retrieval of cloud-top heights (CTHs) from liquid water clouds using a 3-GHz radar. As explained in section 2, there are many types of targets that can interact with a 3-GHz radar signal. This observation, together with low 3-GHz radar signals produced by liquid water clouds, will lead to errors which we quantified for the case study periods. In order to evaluate the reliability of the $3-\mathrm{GHz}$ radar CTHs, they were compared with coincident $94-\mathrm{GHz}$ radar measurements for cases selected over a 3 month time period from May through July 2003. Using 94-GHz radar reflectivities and coincident satellite radiances, we ensured that each case solely consisted of low-altitude liquid water clouds during the study period. 
As a test of the utility of 3-GHz radar cloud-top height retrievals for the validation of satellite-derived cloud-top heights, Multiangle Imaging Spectro-Radiometer (MISR) stereoderived cloud-top heights were compared with both the 94-GHz and 3-GHz radar cloud-top height retrievals for some of the aforementioned case studies. The MISR stereo-derived heights were obtained from the latest operational collection (version F05) including the BestWind product in which cloud-top heights are corrected for wind advection using the best operational wind retrieval (Zong et al., 2002). In section 2 we also present the technique that we used to retrieve cloud-top heights from the $3-\mathrm{GHz}$ radar measurements as well as our methods for comparing $94-\mathrm{GHz}$ and $3-\mathrm{GHz}$ radar retrievals with each other and with the MISR retrievals. We present and discuss the results of our comparisons between the $3-\mathrm{GHz}$ and $94-\mathrm{GHz}$ radar cloud-top heights in section 3, whilst section 4 shows the results of the comparisons between the $94-\mathrm{GHz}$ and 3-GHz radar-derived cloud-top heights with those retrieved from MISR observations. The conclusions of this study follow in section 5.

\section{Methods}

\section{a. 3-GHz radar cloud-top height retrievals}

The 3-GHz radar is not fully automated and operators were needed to perform Range Height Indicator (RHI) scans around the NASA EOS Terra overpass times on those dates when the narrow swath of MISR contained the CFARR site. The RHI scans consisted of vertical slices obtained by varying the dish elevation angle from nearly $0^{\circ}$ to $90^{\circ}$ at a fixed azimuth angle. The beam width of the CAMRa system is $0.25^{\circ}$, its near-field range is effectively $5 \mathrm{~km}$ and its pulse length is $0.5 \mu \mathrm{s}$ or $150 \mathrm{~m}$. Range gate resolution along the beam was selected to be $300 \mathrm{~m}$ to improve the minimum detectable reflectivity by $6 \mathrm{~dB}$. Hydrometeors can be detected at distances of up to $90 \mathrm{~km}$ from the CAMRa system, beyond which the measurements are not digitized. In this study we restricted the observational area to a $50-\mathrm{km}$ radius around the radar, omitting the $5 \mathrm{~km}$ near-field radius area immediately surrounding the radar. The minimum detectable radar reflectivity factor at $30 \mathrm{~km}$ was estimated to be approximately $-13 \mathrm{dBZ}$.

A series of measurements in cloudy situations, coincident with TERRA overpasses, were made during 2003. All of the cases that we chose to study here were selected using the following criteria: 1) no $3-\mathrm{GHz}$ echoes above $5 \mathrm{~km}$ were observed on the RHI plots; 2) the 94-GHz radar detected only low clouds for a period of at least one hour centered on the TERRA overpass time; 3) coincident satellite imagery and cloud-top height retrievals from MODIS (MODerate resolution Imaging Spectroradiometer) and MISR (both on TERRA) did not show high clouds in a significant area around the site.

Liquid water clouds have a low radar reflectivity compared to that from rain or ice cloud, so by setting lower and upper limit thresholds on reflectivity one can isolate areas where liquid water clouds may be present. Knight and Miller (1993) found values of Z between -20 and $-15 \mathrm{dBZ}$ at 5-cm radar wavelengths for liquid water clouds that were just developing, and found values up to $-10 \mathrm{dBZ}$ in liquid water clouds in the environs of Hawaii. While stratocumulus clouds produce signals as low as $-50 \mathrm{dBZ}$ or less, we chose $40 \mathrm{dBZ}$ as our lower limit threshold on liquid water cloud reflectivities. We made this choice because a reflectivity of $-40 \mathrm{dBZ}$ corresponds to signals below the instrumental noise level for clouds $5 \mathrm{~km}$ from the CAMRa system. As an upper limit on liquid water cloud reflectivity, we chose a maximum value of $0 \mathrm{dBZ}$. This allows for dense clouds, such as 
cumulonimbus, to be included in the samples studied while eliminating periods of precipitation that contain substantially more precipitation than drizzle.

Since the CAMRa system has polarization capabilities, the differential reflectivity $Z_{\mathrm{DR}}$ was also measured during the three-month period. Differential reflectivity $\left(\mathrm{Z}_{\mathrm{DR}}\right)$ is the ratio of the reflectivity $\left(Z_{\mathrm{h}}\right)$ observed with transmitted and received signals of horizontal polarization to that $\left(Z_{\mathrm{v}}\right)$ observed with signals of vertical polarization: $Z_{\mathrm{DR}}=10 \log \left(\mathrm{Z}_{\mathrm{h}} / \mathrm{Z}_{\mathrm{v}}\right)$.

For off-zenith measurements, the differential reflectivity is $0 \mathrm{~dB}$ for spherical particles, whereas oblate particles, such as raindrops or ice crystals, produce positive values. We interpreted differential reflectivities that fell between $-0.5 \mathrm{~dB}$ and $0.5 \mathrm{~dB}$ as coming from small, spherical liquid-water droplets. This range was chosen so that potential errors in calibration would not hinder the detection of spherical particles. Note that this range is also in accordance with what is shown in the automated target detection and classification of Vivekanandan et al. (1999). This approach does not exclude from the study some clouds that contain raindrops and ice particles. However, these particles will not be present above cloud top and will not cause any additional uncertainty in retrieved cloud-top heights.

Miller et al. (1998) showed that a 3-GHz radar alone could not be used for automated cloud detection because insects, birds, ground clutter or clear air Bragg scattering could give rise to echoes similar to clouds. Insects at CFARR tend to exhibit large $Z_{\mathrm{DR}}$, much greater than $1 \mathrm{~dB}$ (e.g. Zrnic and Ryzhkov, 1999), and birds will cause large $Z_{\mathrm{h}}$ (Nebuloni and Capsoni, 2004). Ground features, such as trees, buildings, hills or poles, can contribute significantly to the radar signal contaminating the signal from purely atmospheric targets. Fortunately, these ground clutter power returns are fairly constant in time and can be identified and characterized from power returns during clear sky periods. (Ground clutter filters exist for this purpose but none are presently in place at CFARR.) The ground-clutter returns from a clear sky period can subsequently be removed from cloudy sky returns by subtraction. For our case study periods, we used clear sky scans obtained on 8 August 2003 to characterize the static component of the clutter and removed it from our cloudy sky returns. This was achieved by considering as static clutter any signal in the clear scans that had a differential reflectivity outside of the range from $-0.1 \mathrm{~dB}$ to $0.1 \mathrm{~dB}$. The reason for choosing this range was dictated by the presence of another potential source of contamination in the form of clear air refractivity gradients, or Bragg scattering, caused by incoherent turbulence mixing in clear air (Battan, 1973). Bragg scattering cannot be distinguished easily from cloud signals (i.e. "Rayleigh" scattering) because both effects exhibit similar reflectivity factors and differential reflectivities.

Bragg scattering is actually the most probable source of contamination in our cloud signals, causing some clear areas to be detected as cloudy (Knight and Miller, 1993). Moreover, while studying radar echoes from clouds in convective regions, Knight and Miller (1993) found that Bragg scattering was particularly important at the sides and edges of clouds (see also Battan, 1973), in areas where no hydrometeors could be found. This is a problem for cloud-top height detection as it potentially can bias 3-GHz radar retrievals of cloud-top height, as much as $500 \mathrm{~m}$ in some of the cases studied by Knight and Miller (1993). As a result, 3-GHz radars cannot be used as standalone cloud detection instruments.

Radars, like CAMRa, with a $10-\mathrm{cm}$ wavelength are far more sensitive to Bragg scattering than shorter wavelength radars, such as the 35- and 94-GHz radars at CFARR. In order to decipher Bragg scattering from Rayleigh scattering by hydrometeors, Knight and Miller (1993, 1998) suggest the use of a dual-wavelength radar system with the different 
radars having different sensitivities to Bragg scattering. In this scenario reflectivity differences between the two radars can be used to separate Bragg scattering from Rayleigh scattering. Unfortunately, only one radar was mounted on the CAMRa dish at the time of this study, although a $1275-\mathrm{MHz}$ radar was installed after our study. Erkelens et al. (2001) proposed that there is a third scattering mechanism, i.e. coherent scattering in clouds caused by fluctuations in liquid water mixing ratio. This coherent scattering would cause water droplets to display a stronger signal than expected, especially at longer wavelengths. This latter effect could be beneficial for our case study periods for which the clouds have a very weak Rayleigh scattering signal. All in all, the main source of uncertainty in the 3-GHz radar cloud-top height retrieval that we must evaluate arises from Bragg scattering near cloud top.

Removing the ground clutter power from the cloudy sky returns and applying the reflectivity and differential reflectivity thresholds to the results resulted in a cloud mask that shows, as a function of range and elevation angle, the areas where a liquid-water cloud may be present. Processing RHI scans as described above and transforming the range-elevation angle gridded returns to altitude and horizontal distance from the CFARR site, we arrived at a cloud mask with vertical and horizontal resolutions of $100 \mathrm{~m}$ and $300 \mathrm{~m}$ respectively -- 300 $\mathrm{m}$ along the horizontal to match the range resolution of the radar and $100 \mathrm{~m}$ along the vertical to allow for better precision in the cloud-top height estimates. We emphasize that the 3-GHz radar scans do not provide information on clouds near the surface because of significant surface clutter. Consequently, the full vertical extent of clouds close to the surface cannot be obtained. Therefore, in this study we were limited to using the $3-\mathrm{GHz}$ radar returns near cloud tops.

b. Methods for comparison with 94-GHz radar cloud-top heights

The 3-GHz radar cloud-top heights (CTHs) were extracted and compared with coincident $94-\mathrm{GHz}$ radar $\mathrm{CTHs}$ to provide an estimate of the veracity of the 3-GHz radar retrievals. Vertically pointing $94-\mathrm{GHz}$ radar provides temporal variations of CTH above the CFARR site. The 3-GHz radar CTHs were collected as part of a series of elevation scans along given azimuths, providing useful data for approximately $30 \mathrm{~km}$ beginning at $20 \mathrm{~km}$ from the CFARR site. The near field of CAMRa actually extends out to $12.5 \mathrm{~km}$, although the data are of good quality beyond about $5 \mathrm{~km}$ from the radar. We found the ground-clutter signal to be quite strong within $20 \mathrm{~km}$, so we decided to use only data beyond a $20 \mathrm{~km}$ range. Beyond $50 \mathrm{~km}$, the radar returns from liquid water cloud droplets are too weak and too sparse to be meaningful.

In order to collocate the $94-\mathrm{GHz}$ vertically pointing radar measurements with the 3 $\mathrm{GHz}$ radar spatially scanned measurements, we first determined which of the 3-GHz radar scan azimuth angles was in the direction of the wind. To this end, we calculated the median CTH for each scan direction over distances of $20 \mathrm{~km}$ to $50 \mathrm{~km}$ from the CFARR site. We then interpolated radiosonde (RS) observations of wind speed and direction collected at Larkhill $\left(51.12^{\circ} \mathrm{N}-1.48^{\circ} \mathrm{W}\right)$, which is approximately $30 \mathrm{~km}$ from the CFARR site, to the median $\mathrm{CTH}$ retrieved from each scan. We then selected the scan for which the difference between the azimuth angle and the wind direction at the median CTH was at a minimum for comparison of the $3-\mathrm{GHz}$ and $94-\mathrm{GHz}$ radar retrieved CTHs. Using the wind speed interpolated to the median $\mathrm{CTH}$, we then estimated the time period over which the clouds detected by the 3-GHz radar would eventually drift over the CFARR site.

For our procedure to work properly the wind must not vary drastically from Larkhill to Chilbolton and from the radiosonde launch-time, usually 10:00 UT, to the time of the 3- 
$\mathrm{GHz}$ radar scans. Because of the uncertainties caused by wind heterogeneities across the 30 $\mathrm{km}$ distance between Larkhill and CFARR and the fact that we could not always find an exact match between the wind direction and the $3-\mathrm{GHz}$ radar scan azimuth angles, a range gate to range gate comparison between 3- and 94-GHZ radar CTHs was not always possible. Consequently, we compared the median values over the $20 \mathrm{~km}$ to $50 \mathrm{~km}$ range of $3-\mathrm{GHz}$ radar CTHs obtained from a single RHI with the median values of 94-GHz radar CTHs over the time period just discussed.

c. Methods for comparison between MISR and radar cloud-top heights

For comparison between the 94-GHz radar zenith pointing measurements of cloudtop height and MISR BestWind cloud-top heights, we computed both the MISR median CTHs within a variety of latitude-longitude boxes centered on the CFARR site and the 94$\mathrm{GHz}$ radar median CTHs over several time periods centered on the MISR overpass time. The MISR latitude-longitude boxes were of size $\pm 0.02^{\circ}, \pm 0.05^{\circ}, \pm 0.1^{\circ}$ and $\pm 0.2^{\circ}$, while the corresponding time periods over which we computed the median $94-\mathrm{GHz}$ radar $\mathrm{CTHs}$ were 5, 10, 20 and 40 minutes.

For comparison between 3-GHz radar and MISR CTHs, we start with the fact that both the MISR and 3-GHz radar produced spatially distributed cloud-top height retrievals as a function of time. Consequently, spatially distributed CTHs could be compared, leading to a much larger sample size for these comparisons. For a MISR overpass of the CFARR site we aligned each 3-GHz radar scan of CTHs with the MISR CTHs that were closest. Consequently, we were able to compare a single 3-GHz radar $\mathrm{CTH}$ retrieval with a single, neighbouring value retrieved from MISR. In this approach we assume that the time difference of 10 minutes on average between $3 \mathrm{GHz}$ RHI scan pixels and the corresponding instantaneous MISR CTH pixel played an insignificant role.

\section{Comparison between 3-GHz and 94-GHz radar cloud-top heights}

There were 9 dates, given hereafter in the format year-month-day_of_month, for which a low-altitude liquid water cloud was detected by both the $94-\mathrm{GHz}$ and 3-GHz radars: 200305-02, 2003-05-09, 2003-05-20, 2003-06-05, 2003-06-19, 2003-06-24, 2003-06-26, 200307-02 and 2003-07-04. Additionally, we used cloud base information from the ceilometer (Cloud Base Best Estimate, or CBBE) to characterize the cloud vertical extent for these 9 cases (Clothiaux et al., 2000). All cloud-top and cloud-base heights are given in terms of altitude (in $\mathrm{km}$ ) above the surface ellipsoid of the Earth (WGS84). A brief description of the synoptic situation and cloud type for each case is given in Table 1. Table 1 also provides the median values of 3-GHz radar CTHs, 94-GHz radar CTHs and CBBE with their associated standard deviations for the corresponding sampling distance and periods. The differences never exceeded $0.7 \mathrm{~km}$ and no correlation of the difference was found for either the difference between the 3-GHz radar scan azimuth angle and the wind direction nor the 3$\mathrm{GHz}$ and $94-\mathrm{GHz}$ radar reflectivity factors at cloud top. The case for which the $94-\mathrm{GHz}$ radar $\mathrm{CTH}$ exceeded the $3-\mathrm{GHz}$ radar $\mathrm{CTH}$ by the largest amount $(0.7 \mathrm{~km})$ occurred on 2003-06-19 whereas the ones for which the 3-GHz radar CTH was much larger than the 94GHz radar CTH (-0.5 km) occurred on 2003-05-09 and 2003-07-02.

Because the wind measurements were performed $30 \mathrm{~km}$ from the radars, and also because wind variability in the vertical may be important, we assessed how a change in wind direction and speed would affect the 3- and 94-GHz radar CTH comparisons. To this end we computed the variability of CTHs retrieved with the $3-\mathrm{GHz}$ radar across all scans available 
for each case study period. We found that the standard deviation in median $3-\mathrm{GHz}$ radar CTHs for all scan azimuth angles within a case study period varied from 0.1 to $0.8 \mathrm{~km}$ across the 9 case study periods. Moreover, the standard deviations of the 3-GHz radar CTHs were not correlated with the difference with $94-\mathrm{GHz}$ radar CTHs nor with the difference between scan azimuth angle and the wind direction. All 9 cases had minor cloud-top height variations across the scanned area and there were no apparent errors introduced into our comparisons resulting from our choice of wind direction. Errors in wind speed affect the time period chosen to sample the $94-\mathrm{GHz}$ radar CTHs. We found that the standard deviation of 94-GHz radar CTH for each case never exceeded $0.4 \mathrm{~km}$ and was not correlated with the difference between the 94- and 3-GHz radar CTHs.

Figures 1, 2 and 3 show for each date the 94-GHz radar reflectivity factor as a function of time and altitude, the 3-GHz radar reflectivity factor as a function of distance and altitude and the 3-GHz radar cloud-top heights as a function of distance, respectively. Overall, the average difference between the two radar CTHs was $-0.1 \pm 0.4 \mathrm{~km}$ with a squared correlation of 0.42 . While we attempted to remove clutter, i.e. ground-clutter and airborne non-hydrometeors, and precipitation returns from the analysis, any missed detections of these signals will introduce errors. Moreover, any significant returns from Bragg scattering will also introduce uncertainties into the analysis.

We found that when the 94-GHz radar signal was weak and the cloud continuous (i.e. case study periods 2003-06-19, 2003-06-24 and 2003-07-04; Figures 1d, 1e and 1i), the 3-GHz radar CTH was invariably lower than the $94-\mathrm{GHz}$ radar $\mathrm{CTH}$, presumably because the 3-GHz radar is more sensitive to larger particles towards the base of the cloud. When clouds were continuous and the $94-\mathrm{GHz}$ radar signals were strong, the agreement between the two instruments was excellent with 3-GHz radar CTHs slightly larger than $94-\mathrm{GHz}$ radar CTHs (Figure 1a). When clouds were irregular, the sign of the CTH differences varied and there was no obvious relationship of these differences with the strength of the 94-GHz radar returns. Two cases with precipitating cells were found (Figures $1 \mathrm{c}$ and $1 \mathrm{~h}$ ). For the period of 2003-05-20 the 3-GHz radar CTHs were lower than the 94-GHz radar CTHs. However, since precipitating cells alternate with non-precipitating areas and always have a CTH higher for the former than the latter, the 3-GHz radar CTHs should generally be lower than the 94$\mathrm{GHz}$ radar values as the precipitating areas are not considered in the study. For the period on 2003-07-02 the 3-GHz radar CTHs were larger than those derived from the 94-GHz radar. However, the cloud-top heights increased rapidly over the CFARR site on this day, so the difference can easily come from errors in evaluating the coincidence time period for the 94-GHz radar CTHs.

The other three cases are broken cloud situations (Figures 1b, 1f, 1g), which are difficult to analyze accurately with the coincidence methods that we had available to us for our study. Moreover, these clouds do not have strong $94-\mathrm{GHz}$ radar signals so they will not be readily detected by the $3-\mathrm{GHz}$ radar, especially in the presence of ground clutter and Bragg scattering.

For those 5 cases for which the cloud-top height differences were within $0.2 \mathrm{~km}$, we find that their squared correlation is 0.80 .

\section{Comparison between MISR and 3- and 94-GHz radar cloud-top heights}

During our period of study, there were 6 occurrences of coincident MISR overpasses over the CFARR site when low altitude clouds were present and 94-GHz radar data were 
available. In addition to 2003-05-02, 2003-05-09, 2003-06-19 and 2003-06-26, two new cases were added of 2003-05-27 and 2003-06-12. In comparisons of the MISR median CTHs with the 94-GHz radar CTHs we found that best agreement, at least in terms of lower standard deviations and higher correlations, occurred when CTHs from the longest radar time period (i.e., 40 minutes) and the $0.1^{\circ}$ latitude-longitude box were used in the comparison. This particular combination of averaging time and box size produced an average difference of $0.1 \pm 0.3 \mathrm{~km}$, which is far lower than the theoretical $0.562 \mathrm{~km}$ uncertainty and estimated $1 \mathrm{~km}$ uncertainty in MISR stereo-derived CTHs based on intercomparisons with surface Digital Elevation Models (Muller et al., 2002). Statistics for the six case study periods are presented in Table 2. This table shows that, apart for 2005-05-02, MISR CTHs are always slightly lower than 94-GHz radar CTHs. Case 2003-05-02 reveals that the MISR wind correction (which is based on a $70.6 \mathrm{~km}$ block) changed significantly from north of the CFARR site to south of the site, so creating an artificial step in the MISR CTHs. The wind correction for the north of the CFARR region may be in error, leading to MISR CTHs that are too high in altitude.

We then compared MISR CTHs with 3-GHz radar CTHs for the 4 cases (i.e. 200305-02, 2003-05-09, 2003-06-19 and 2003-06-26) when MISR and both radars were functioning. Table 3 summarizes the MISR and 3-GHz radar CTHs as well as their height differences and the number of pixels compared. Overall, when including all pixels for all dates and all available scans, we found an average cloud-top height difference between the $3-\mathrm{GHz}$ radar and MISR of $-0.2 \pm 0.6 \mathrm{~km}$. In accordance with the MISR and 94-GHz radar observations on 2003-05-02, MISR CTHs are much greater than the 3-GHz radar CTHs for all scans situated to the northwest of CFARR. In fact, we observed a difference of approximately $1 \mathrm{~km}$ between MISR CTHs to the northwest of CFARR and those to the southwest of the site. In the sector southwest of CFARR, 3-GHz radar and MISR CTH differences are down to $-0.2 \pm 0.2 \mathrm{~km}$, with MISR CTHs still larger than those from the 3$\mathrm{GHz}$ radar, suggesting that the MISR wind correction could also be slightly overestimated here as well.

On 2003-06-19, we have already seen that the clouds did not return a strong 3-GHz radar signal, so we expected the MISR CTHs to be slightly higher than those from the 3$\mathrm{GHz}$ radar. In fact, the mean cloud-top height difference for this period is $-0.5 \pm 0.2 \mathrm{~km}$, agreeing with our expectation. For 2003-05-09, the cloud-top height differences between the two instruments was small. Cumulus clouds, even broken ones, present no detection problems for the 3-GHz radar and the MISR cloud-top height retrieval performed well on these clouds also. (See Figure 4 for an example of 3-GHz radar and MISR cloud-top heights.) Finally, the 2003-06-26 case shows MISR CTHs lower than the 3-GHz radar CTHs with a difference of $0.3 \pm 0.4 \mathrm{~km}$, not dissimilar to what we found when comparing MISR CTHs with 94-GHz radar CTHs.

These four cases demonstrate that $3-\mathrm{GHz}$ radar observations can provide useful cloud information for comparison with satellite cloud-top height retrievals in a 2D transect. In fact, for these cases, the conclusions that we draw from the 3-GHz radar data are similar to the conclusions that we obtained from the $94-\mathrm{GHz}$ radar data. In one case for which we compared 3-GHz radar and MISR CTHs, the 3-GHz radar returns from the stratocumulus clouds in this case were too weak to be of value. Insofar as the MISR cloud-top height retrievals are concerned, we found them to have a slight low bias for two cases and problems with their wind correction for one case. 


\section{Conclusions}

The aim of this study was to explore the potential of 3-GHz radar observations in retrieving the cloud-top heights of low-altitude liquid water clouds in the environs of the CFARR site. Using 9 case study periods, we have found that we could retrieve cloud-top heights of low-altitude liquid water clouds using a 3-GHz radar obtaining agreement within $0.7 \mathrm{~km}$ in comparisons with more accurate $94-\mathrm{GHz}$ radar cloud-top height estimates. We found that low liquid water content stratocumulus clouds cause the largest uncertainties in the 3-GHz radar retrievals as their echoes are close to radar receiver noise. Considering potential contamination by airborne non-hydrometeors and Bragg scattering, whose effects we could not clearly identify in the $3-\mathrm{GHz}$ radar signals, the 3-GHz radar cloud-top height retrievals were nonetheless showing skill relative to the cloud-top heights derived from the 94-GHz radar, with average differences of $-0.1 \pm 0.4 \mathrm{~km}$.

One possible use for the 3-GHz radar cloud-top height retrievals is for the validation of cloud-top heights derived from satellite measurements. To this end we compared MISR BestWind (version 5) cloud-top heights with both 94-GHz and 3-GHz radar cloud-top heights. Comparisons with 94-GHz radar CTHs were conducted on 6 occasions and revealed a tendency for MISR CTHs to be biased slightly low by $0.1 \pm 0.3 \mathrm{~km}$ relative to the $94-\mathrm{GHz}$ radar CTHs.

A comparison between MISR and 3-GHz radar CTHs was performed on four days in which we used all available $3-\mathrm{GHz}$ radar observations at $20 \mathrm{~km}$ to $50 \mathrm{~km}$ distances from the CFARR site. The average CTH difference calculated over more than 1,500 cloud-top height retrievals was $-0.2 \pm 0.6 \mathrm{~km}$, meaning that, at least for low-altitude liquid water clouds, MISR CTHs matched those from the 3-GHz radar well, being within the measured expected accuracy of $1 \mathrm{~km}$ for clear conditions and the theoretical accuracy of $0.562 \mathrm{~m}$ (Muller et al., 2002) and within $1.5 \mathrm{~km}$ in cloudy single layer situations (Naud et al., 2002; Naud et al., 2004). A more detailed analysis of the differences revealed that on two occasions, MISR cloud-top heights were biased low, whereas the other two occasions revealed problems with the MISR wind correction and the reliability of 3-GHz radar signals from weakly reflecting liquid water clouds.

Combined measurements using the ceilometer, the $94-\mathrm{GHz}$ and the $3-\mathrm{GHz}$ radars at CFARR provide a means of establishing some two-dimensional cloud-top surface structures around the CFARR site. For this purpose, however, most of the cases used here would probably not be appropriate because the scans did not cover a dense enough area, the range gate spacing and resolution volume of $300 \mathrm{~m}$ were not optimal (for clouds with higher reflectivities the maximum possible range resolution of $75 \mathrm{~m}$ would be better, although this also implies a loss in CAMRa sensitivity), and sampling the full 360 degrees in azimuth during both clear and cloudy skies was not performed. Nonetheless, it is possible to remove these current limitations in future observational campaigns.

Using the synergy available with data from the multiple instruments at the CFARR site, 3-GHz radar observations can provide useful cloud-top height information for lowaltitude liquid water clouds with an accuracy of about $0.4 \mathrm{~km}$, which is at present sufficiently accurate for validation of satellite-derived cloud-top heights. However, as expected, 3-GHz radar cloud-top height accuracy decreases for clouds with low liquid water contents and small particle sizes, as well as in the environs of intense precipitation. Finally, although most measurements will tend to suffer from contamination by Bragg scattering, we have shown that this does not necessarily undermine the value of the data. 
For the CFARR CAMRa 3-GHz radar to be fully exploited for cloud studies, the more sophisticated approach developed at Reading University for clear air ground-clutter detection at the site should be implemented. In addition, it would be useful to establish the accuracy with which cloud-top height of other cloud types, such as convective, mixed-phase and ice clouds, can be determined. This is to be the subject of future research.

\section{Acknowledgements}

This research was supported by the European Commission under contract EVG1-CT2000-00033 (CLOUDMAP2). The MISR data of validated quality were obtained from the NASA Langley Research Center Atmospheric Sciences DAAC. Eugene Clothiaux was also supported by the Office of Biological and Environmental Research of the U.S. Department of Energy (under Grant DE-FG02-90ER61071) as part of the Atmospheric Radiation Measurement (ARM) Program. The CAMra radar is funded by the Chilbolton Facility Consortium (NERC, OFCOM, EPSRC, CCLRC). The authors would like to express their gratitude to Charles Kilburn (RAL) and Tim Smyth (PML) for their help and the reviewers for their detailed comments. 


\section{References}

Ackerman T. P. and G. M. Stokes, 2003: The Atmospheric Radiation Measurement program. Physics Today, 56 (1).

Battan L. J., 1973: Radar observation of the atmosphere. The University of Chicago press, 324pp.

Clothiaux E. E., T. P. Ackerman, G. C. Mace, K. P. Moran, R. T. Marchand, M. A. Miller and B. E. Martner, 2000: Objective determination of cloud heights and radar reflectivities using a combination of active remote sensors at the ARM CART sites. J. Appl. Meteorol., 39, 645-665.

Erkelens J. S., V. K. C. Venema, H. W. J. Russchenberg and L. P. Ligthart, 2001: Coherent scattering of microwaves by particles: evidence from clouds and smoke. J. Atm. Sci., 58 (9), 1091-1102.

Goddard J. W. F., J. D. Eastment and M. Thurai, 1994: The Chilbolton Advanced Meteorological radar: a tool for multidisciplinary atmospheric research. Electron. Commun. Eng. J., 6 (2), 77-86.

Hogan R. J. and A. J. Illingworth, 2000: Deriving cloud overlap statistics from radar. Q. J. R. Meteorol. Soc., 126, 2903-2909.

IPCC, 2001: Climate change 2001: The scientific basis. Cambridge University press, $882 \mathrm{pp}$.

Knight C. A. and L. J. Miller, 1993: First radar echoes from cumulus clouds. Bull. Amer. Meteorol. Soc., 74 (2), 179-188.

Knight C. A. and L. J. Miller, 1998: Early radar echoes from small, warm cumulus: Bragg and Hydrometeor scattering. J. Atm. Sci., 55, 2974-2992.

Miller M. A., J. Verlinde, C. V. Gilbert, G. J. Lehenbauer, J. S. Tongue and E. E. Clothiaux, 1998: Detection of nonprecipitating clouds with the WSR-88D: a theoretical and experimental survey of capabilities and limitations. Weath. Forecast., 13, 1046-1062.

Muller J.-P., A. Mandanayake, C. Moroney, R. Davies, D. J. Diner and S. Paradise, 2002: MISR stereoscopic image matchers: techniques and results. IEEE Trans. Geosci. Remote Sens., 40 (7), 1547-1559.

Naud C., J.-P. Muller and E. E. Clothiaux, 2002: Comparison of cloud-top heights derived from MISR stereo and MODIS CO $\mathrm{C}_{2}$-slicing. Geophys. Res. Lett., 29 (16), 1795.

Naud C., M. Haeffelin, J.P. Muller, Y. Morille and A. Delaval, 2004: Assessment of MISR and MODIS cloud top heights through inter-comparison with a back-scattering lidar at SIRTA. Geophys. Res. Lett., 31 (4), L04114.

Nebuloni R. and C. Capsoni, 2004: Doppler radar signatures of migrating birds. Proceedings of $30^{\text {th }}$ conference on Radar Meteorology, Jan 11-15, P5.12.

Vivekanandan J., D. S. Zrnic, S. M. Ellis, R. Oye, A. V. Ryshkov and J. Straka, 1999: Cloud microphysics retrieval using S-Band dual-polarization radar measurements. Bull. Amer. Meteorol. Soc., 80 (3), 381-388.

Zong J., R. Davies, J.-P. Muller and D. J. Diner, 2002: Photogrammetric retrieval of cloud advection and top height from the Multi-Angle Imaging Spectroradiometer (MISR). Photogramm. Eng. Remote Sens., 68 (8), 821-829.

Zrnic D. S. and A. V. Ryzhkov, 1999: Polarimetry for weather surveillance radars. Bull. Am. Meteorol. Soc., 80 (3), 389-406. 
Table 1: For each date with inter-comparisons between the $94-\mathrm{GHz}$ and 3-GHz radar-derived cloud-top heights, we provide brief descriptions of the synoptic situation and cloud type, 3and 94-GHz radar median CTHs with standard deviations, as well as the corresponding median Cloud Base Best Estimate (CBBE).

\begin{tabular}{|c|c|c|c|c|c|}
\hline Date & Synoptic situation and cloud type & $\begin{array}{l}\text { Median } \\
\text { 3-GHz } \\
\text { radar } \\
\text { CTH } \\
(\mathrm{km})\end{array}$ & $\begin{array}{l}\text { Median } \\
94- \\
\text { GHz } \\
\text { radar } \\
\text { CTH } \\
(\mathrm{km})\end{array}$ & $\begin{array}{l}\text { Difference } \\
\text { between } \\
\text { 94- and 3- } \\
\text { GHz radar } \\
\text { CTHs }(\mathrm{km})\end{array}$ & $\begin{array}{l}\text { Median } \\
\text { CBBE } \\
(\mathrm{km})\end{array}$ \\
\hline 2003-05-02 (a) & $\begin{array}{l}\text { CFARR just behind a cold front } \\
\text { of an active depression centered } \\
\text { on SW England. Cumulonimbus } \\
\text { clouds. }\end{array}$ & $1.8 \pm 0.5$ & $1.7 \pm 0.3$ & -0.1 & $1.1 \pm 0.3$ \\
\hline 2003-05-09 (b) & $\begin{array}{l}\text { Small convective cumulus clouds } \\
\text { building over the land in a } \\
\text { westerly airstream behind a small } \\
\text { wave system. Parent low situated } \\
\text { to the west of Iceland. }\end{array}$ & $2.1 \pm 0.9$ & $1.6 \pm 0.1$ & -0.5 & $1.5 \pm 0.1$ \\
\hline 2003-05-20 (c) & $\begin{array}{l}\text { Showery WNW airstream behind } \\
\text { successive troughs. } \\
\text { Cumulonimbus clouds. }\end{array}$ & $2.0 \pm 0.6$ & $2.2 \pm 0.3$ & 0.2 & $1.8 \pm 0.3$ \\
\hline 2003-06-05 (d) & $\begin{array}{l}\text { A ridge of high pressure behind a } \\
\text { cold front, with more organized } \\
\text { precipitation coming in from the } \\
\text { Atlantic. Small cumulus clouds. }\end{array}$ & $2.4 \pm 0.8$ & $2.2 \pm 0.4$ & -0.2 & $1.6 \pm 0.3$ \\
\hline 2003-06-19 (e) & $\begin{array}{l}\text { Within the warm sector of a } \\
\text { developing wave although in } \\
\text { close proximity to an Atlantic } \\
\text { anticyclone. Stratocumulus } \\
\text { clouds. }\end{array}$ & $0.9 \pm 0.2$ & $1.6 \pm 0.2$ & 0.7 & $0.8 \pm 0.1$ \\
\hline $2003-06-24$ (f) & $\begin{array}{l}\text { Ridge of high pressure building } \\
\text { in from Azores. Small streets of } \\
\text { cumulus. }\end{array}$ & $1.3 \pm 0.7$ & $1.5 \pm 0.1$ & 0.2 & $1.4 \pm 0.0$ \\
\hline 2003-06-26 (g) & $\begin{array}{l}\text { Troughs of low pressure track } \\
\text { southwestwards in a slack } \\
\text { airstream. Cumulonimbus. No } \\
\text { precipitation, Insects detected by } \\
\text { 94-GHz radar. }\end{array}$ & $1.1 \pm 0.7$ & $1.7 \pm 0.3$ & 0.6 & $1.4 \pm 0.3$ \\
\hline 2003-07-02 (h) & $\begin{array}{l}\text { Troughs of low pressure in a } \\
\text { northerly airflow associated with } \\
\text { a low-pressure system over } \\
\text { Denmark. Cumulonimbus clouds } \\
\text { where showers occur. }\end{array}$ & $2.4 \pm 0.7$ & $1.9 \pm 0.5$ & -0.5 & $1.4 \pm 0.6$ \\
\hline 2003-07-04 (i) & $\begin{array}{l}\text { NNW airstream. Streets of } \\
\text { stratocumulus. }\end{array}$ & $1.6 \pm 0.8$ & $1.8 \pm 0.1$ & 0.2 & $1.6 \pm 0.1$ \\
\hline
\end{tabular}


Table 2: MISR and 94-GHz radar Median CTHs, as well as CBBE, together with the differences between the MISR and 94-GHz radar median CTHs. For these comparisons we used a MISR box size of $\pm 0.1^{\circ}$ and a $94-\mathrm{GHz}$ radar analysis window of $40 \mathrm{~min}$. The "error bars" are the standard deviations within the MISR latitude-longitude box and the $94-\mathrm{GHz}$ radar data time window. The thickness of the cloud layers can be derived by subtracting the Median CBBE from the 94-GHz radar median CTH.

\begin{tabular}{lllll}
\hline Date & $\begin{array}{l}\text { MISR median CTH } \\
\text { for } \pm 0.1^{\circ}(\mathrm{km})\end{array}$ & $\begin{array}{l}\text { 94-GHz radar median } \\
\text { CTH for 40min }(\mathrm{km})\end{array}$ & $\begin{array}{l}\text { Median CBBE } \\
\text { 40min }(\mathrm{km})\end{array}$ & $\begin{array}{l}\text { Difference 94-GHz } \\
\text { radar -MISR } \\
\text { median CTH }(\mathrm{km})\end{array}$ \\
\hline $2003-05-02$ & $2.4 \pm 0.6$ & $1.9 \pm 0.3$ & $1.1 \pm 0.2$ & -0.5 \\
$2003-05-09$ & $1.3 \pm 0.3$ & $1.6 \pm 0.1$ & $1.6 \pm 0.0$ & 0.4 \\
$2003-05-27$ & $1.2 \pm 0.4$ & $1.4 \pm 0.1$ & $0.8 \pm 0.1$ & 0.2 \\
$2003-06-12$ & $1.5 \pm 0.2$ & $1.8 \pm 0.2$ & $1.5 \pm 0.4$ & 0.3 \\
$2003-06-19$ & $1.5 \pm 0.3$ & $1.6 \pm 0.1$ & $1.0 \pm 0.2$ & 0.1 \\
$2003-06-26$ & $1.3 \pm 0.8$ & $1.5 \pm 0.4$ & $1.1 \pm 0.2$ & 0.2 \\
\hline
\end{tabular}


Table 3: Means and standard deviations of MISR BestWind CTHs and 3-GHz radar CTHs, together with corresponding cloud-top height differences, for four case study periods. We also provide the number of 3-GHz radar scans available for each case study and the total number of pixels that we compared. All samples in the comparison were $20-50 \mathrm{~km}$ from the CAMRa site.

\begin{tabular}{llllll}
\hline Date & $\begin{array}{l}\text { MISR mean CTH } \\
(\mathrm{km})\end{array}$ & $\begin{array}{l}\text { 3-GHz radar mean } \\
\mathrm{CTH}(\mathrm{km})\end{array}$ & $\begin{array}{l}\text { Mean difference } \\
\text { 3-GHz radar } \\
\text { MISR CTHs } \\
(\mathrm{km})\end{array}$ & $\begin{array}{l}\text { Total } \\
\text { number of } \\
\text { compared } \\
\text { pixels }\end{array}$ & $\begin{array}{l}\text { Number } \\
\text { of 3-GHz } \\
\text { radar } \\
\text { scans }\end{array}$ \\
\hline $2003-05-02$ & $2.2 \pm 0.6$ & $1.4 \pm 0.2$ & $-0.8 \pm 0.6$ & 663 & 10 \\
$2003-05-09$ & $1.8 \pm 0.1$ & $1.9 \pm 0.2$ & $0.1 \pm 0.2$ & 598 & 10 \\
$2003-06-19$ & $1.3 \pm 0.1$ & $0.7 \pm 0.2$ & $-0.5 \pm 0.2$ & 251 & 14 \\
$2003-06-26$ & $1.1 \pm 0.3$ & $1.3 \pm 0.4$ & $0.3 \pm 0.4$ & 295 & 14 \\
\hline
\end{tabular}




\section{List of figures:}

Figure 1: 94-GHz radar reflectivity factors for all nine case study periods when we compared cloud-top heights derived from the 94- and 3-GHz radars. The two vertical lines delimit the time period that we used to extract the $94-\mathrm{GHz}$ radar median cloud-top heights. Wind data from Larkhill radiosondes were used to infer which 3-GHz radar scans were most likely sampling the clouds detected by the $94-\mathrm{GHz}$ radar. The $3-\mathrm{GHz}$ radar scans were analyzed only from $20 \mathrm{~km}$ to $50 \mathrm{~km}$ in range from the CFARR site. For the nine case study periods, the cloud types are: (a) cumulonimbus, (b) convective cumulus, (c) cumulonimbus, (d) cumulus, (e) stratocumulus, (f) cumulus, (g) cumulonimbus, (h) cumulonimbus, (i) stratocumulus.

Figure 2: 3-GHz radar reflectivity factors for all nine cases when we compared cloud-top heights derived from the 94- and 3-GHz radars. The two vertical lines are $20 \mathrm{~km}$ and $50 \mathrm{~km}$ from the $3-\mathrm{GHz}$ radar and indicate the part of the radar scans that we used in the analysis to estimate the 3-GHz radar-derived median cloud-top heights. Panels (a)-(i) are for the same nine case study periods illustrated in Figure 1.

Figure 3: 3-GHz radar-derived cloud-top heights for all nine cases when we compared cloudtop heights derived from the 94- and 3-GHz radars. Panels (a)-(i) are for the same nine case study periods illustrated in Figures 1 and 2.

Figure 4: Example of a comparison between the MISR BestWind (solid line) and 3-GHz radar-derived (dots) cloud-top heights for the case study period on 2003-05-09. The 3-GHz radar scan for this period was $10^{\circ}$ west of north. The dashed line shows MISR cloud-top heights when no wind correction was applied to the MISR retrievals. 


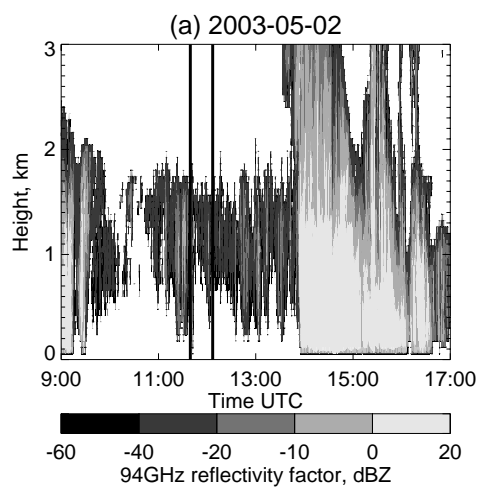

(d) 2003-06-05

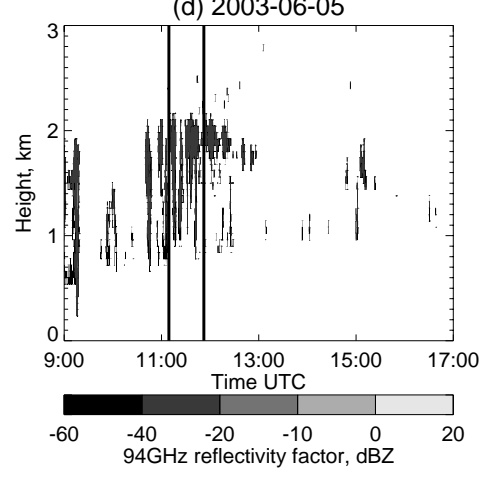

(g) 2003-06-26

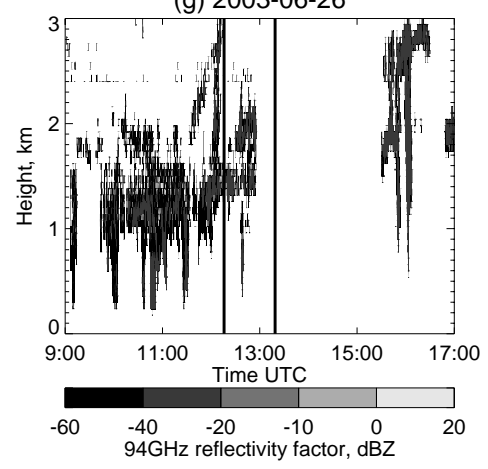

(b) 2003-05-09

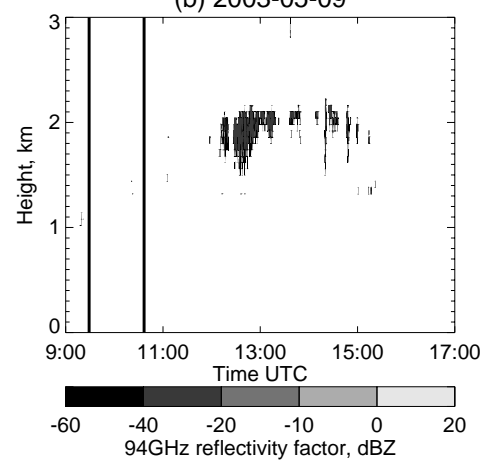

(e) 2003-06-19

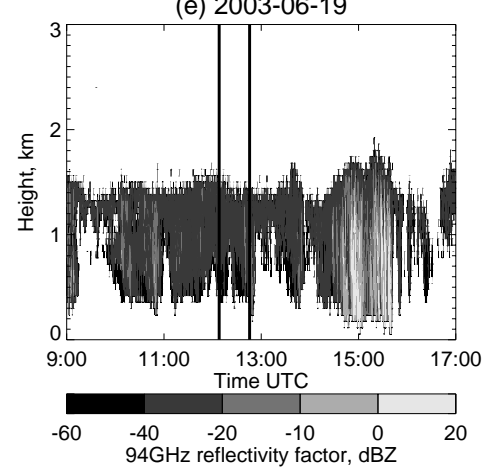

(h) 2003-07-02

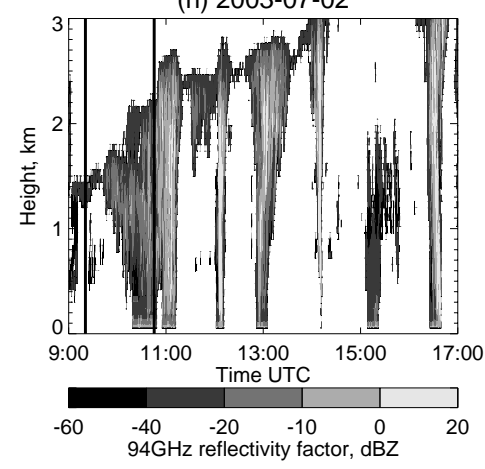

(c) $2003-05-20$

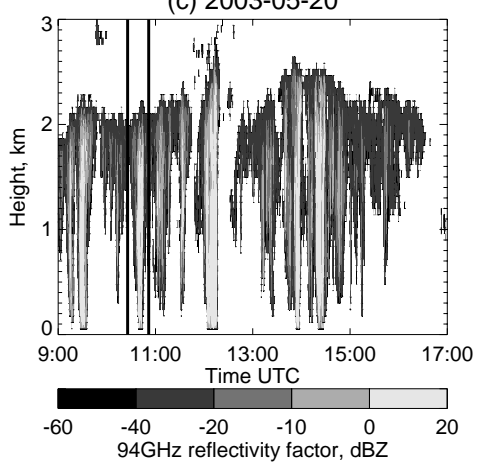

(f) 2003-06-24

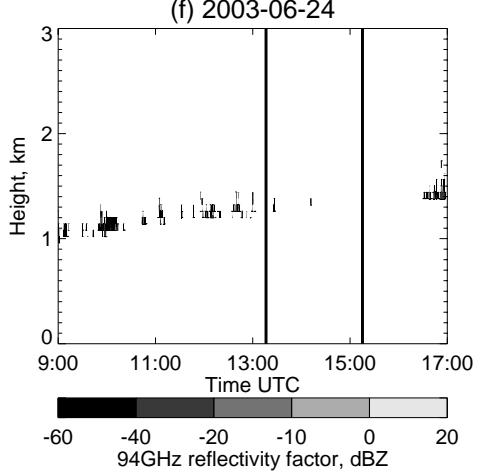

(i) 2003-07-04

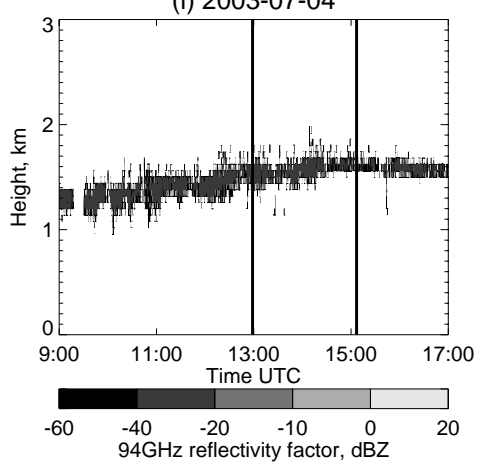

Figure 1: 94-GHz radar reflectivity factors for all nine case study periods when we compared cloud-top heights derived from the 94- and 3-GHz radars. The two vertical lines delimit the time period that we used to extract the $94-\mathrm{GHz}$ radar median cloud-top heights. Wind data from Larkhill radiosondes were used to infer which 3-GHz radar scans were most likely sampling the clouds detected by the $94-\mathrm{GHz}$ radar. The $3-\mathrm{GHz}$ radar scans were analyzed only from $20 \mathrm{~km}$ to $50 \mathrm{~km}$ in range from the CFARR site. For the nine case study periods, the cloud types are: (a) cumulonimbus, (b) convective cumulus, (c) cumulonimbus, (d) cumulus, (e) stratocumulus, (f) cumulus, (g) cumulonimbus, (h) cumulonimbus, (i) stratocumulus. 


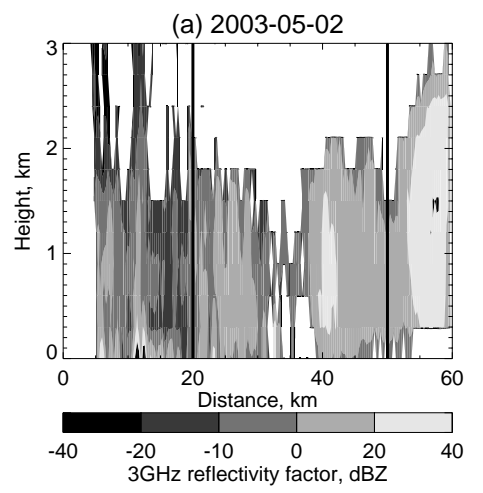

(d) 2003-06-05

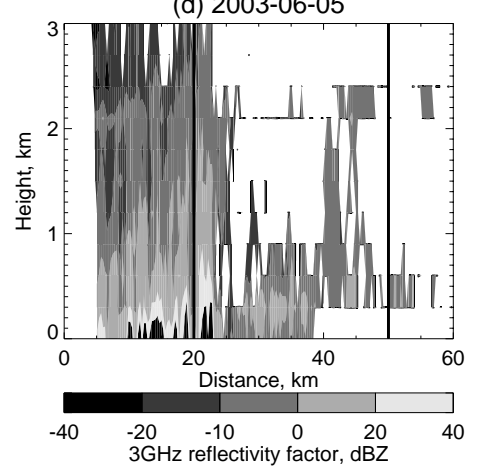

(g) 2003-06-26

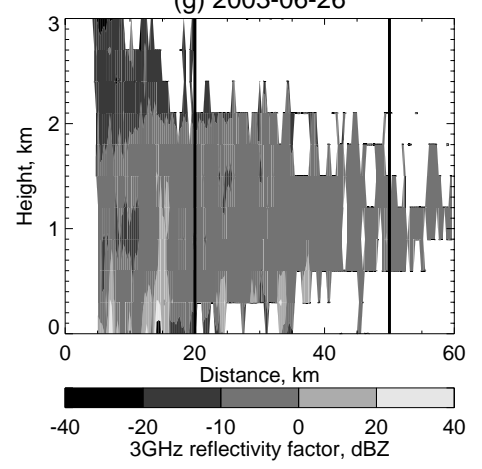

(b) 2003-05-09

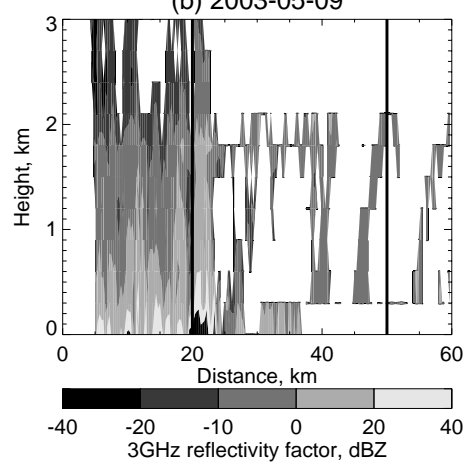

(e) 2003-06-19

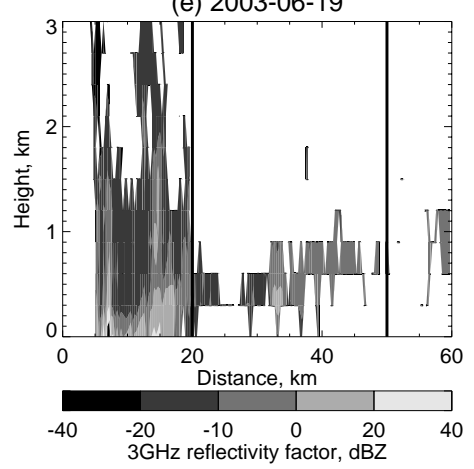

(h) 2003-07-02

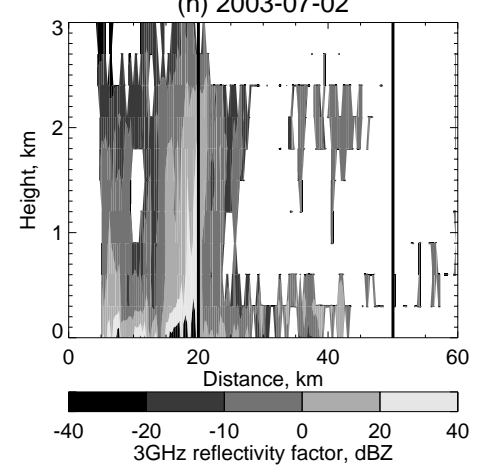

(c) $2003-05-20$

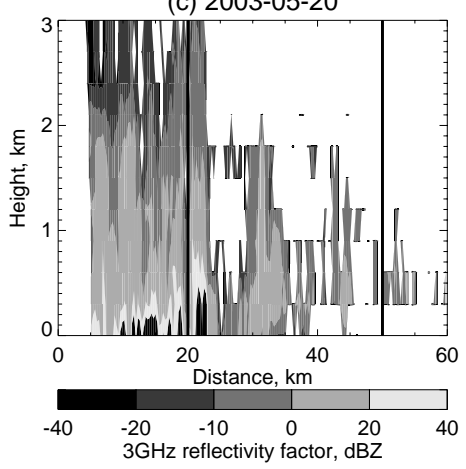

(f) 2003-06-24

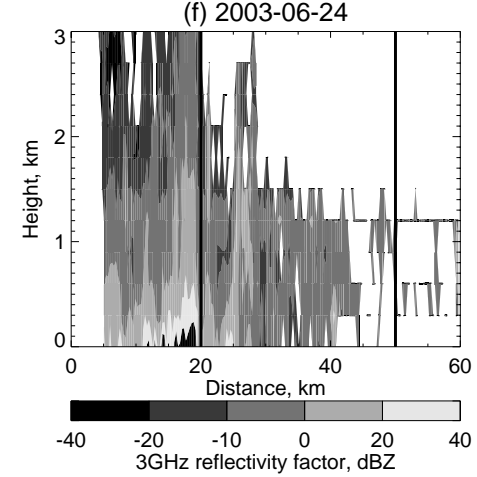

(i) 2003-07-04

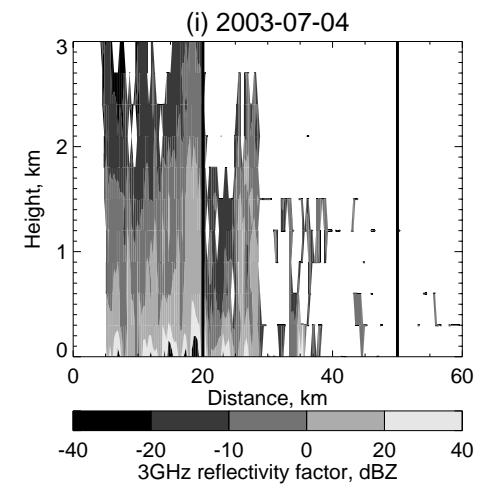

Figure 2: 3-GHz radar reflectivity factors for all nine cases when we compared cloud-top heights derived from the 94- and 3-GHz radars. The two vertical lines are $20 \mathrm{~km}$ and $50 \mathrm{~km}$ from the 3-GHz radar and indicate the part of the radar scans that we used in the analysis to estimate the 3-GHz radar-derived median cloud-top heights. Panels (a)-(i) are for the same nine case study periods illustrated in Figure 1. 
(a) 2003-05-02

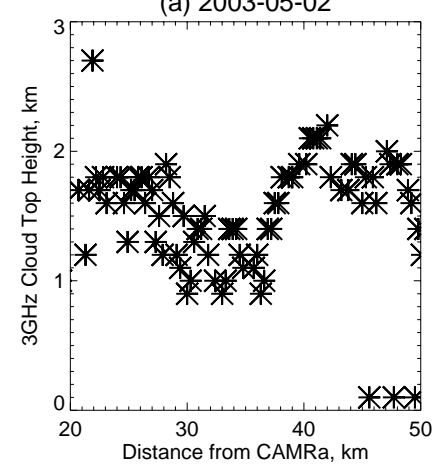

(d) 2003-06-05

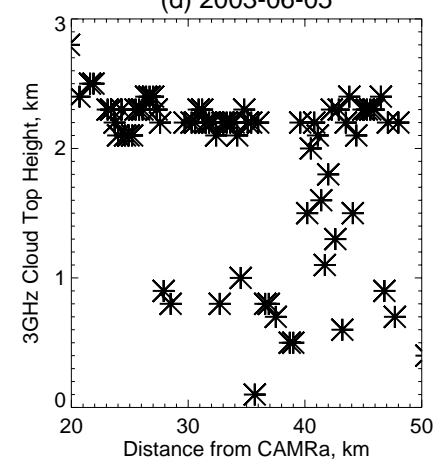

(g) 2003-06-26

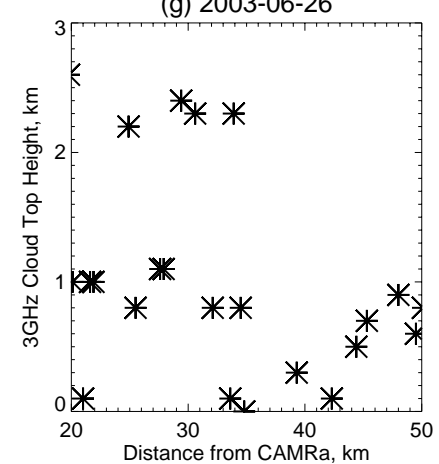

(b) 2003-05-09

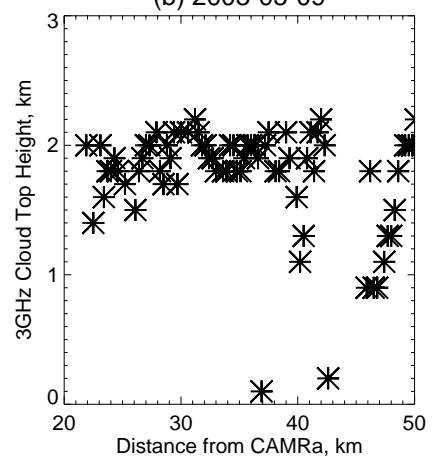

(e) 2003-06-19

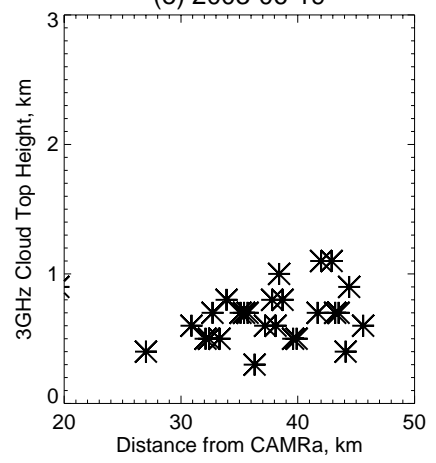

(h) 2003-07-02

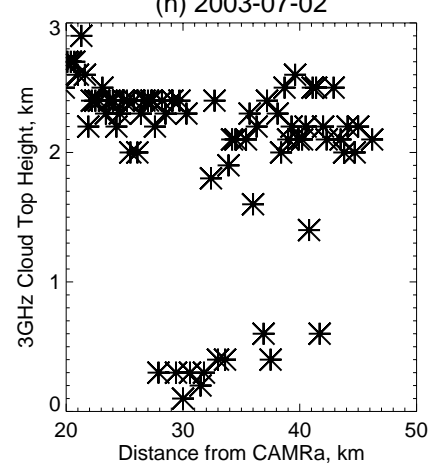

(c) $2003-05-20$

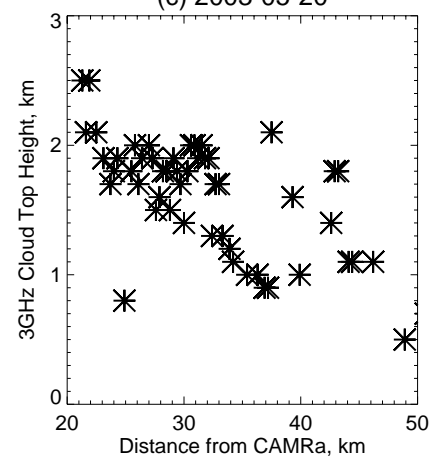

(f) 2003-06-24

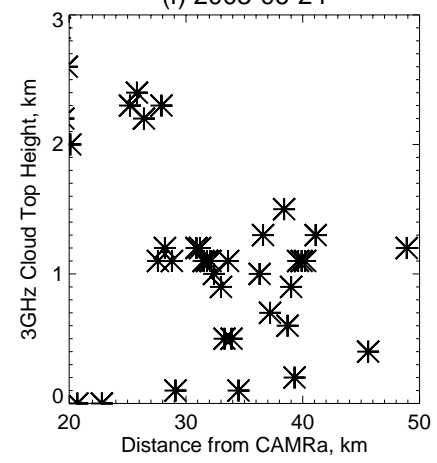

(i) 2003-07-04

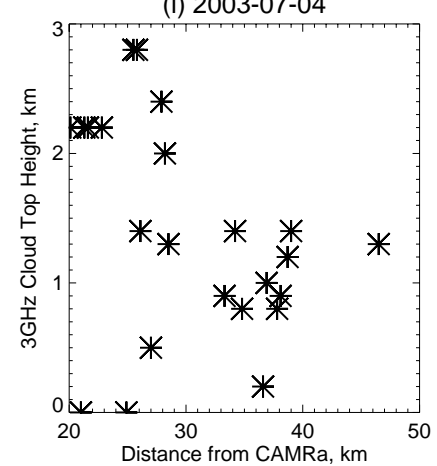

Figure 3: 3-GHz radar-derived cloud-top heights for all nine cases when we compared cloudtop heights derived from the 94- and 3-GHz radars. Panels (a)-(i) are for the same nine case study periods illustrated in Figures 1 and 2. 


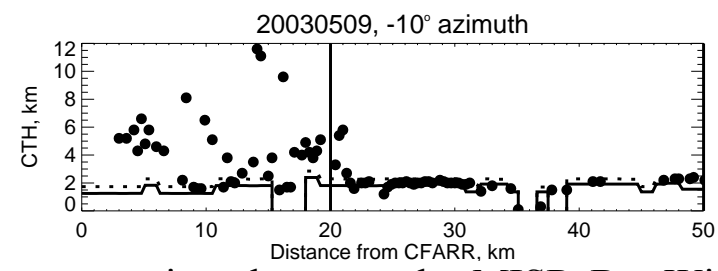

Figure 4: Example of a comparison between the MISR BestWind (solid line) and 3-GHz radar-derived (dots) cloud-top heights for the case study period on 2003-05-09. The 3-GHz radar scan for this period was $10^{\circ}$ west of north. The dashed line shows MISR cloud-top heights when no wind correction was applied to the MISR retrievals. 